\title{
A GRANDE ACELERAÇÃO DICITA: COMO FAZER DELA UMA OPORTUNIDADE PARA TODOS?
}

Ana Paula Assis

Durante 2020, presenciamos um fenômeno de transformação acelerada em níveis sem precedentes na história da humanidade. Como referência, olhemos para a indústria de varejo. Usando dados dos Estados Unidos, entre 2000 e 2020, a participação do e-commerce no setor como um todo cresceu algo como um ponto percentual a cada ano - de aproximadamente 5\% para 16\% no intervalo de vinte anos. Somente no período entre março e abril do ano passado, esse número saltou para $27 \%$. Ou seja, aconteceu em oito semanas o que antes havia levado uma década". Agora, olhemos para um setor muito mais sensivel ao atendimento virtual: saúde. Entre fevereiro e maio de 2020, o atendimento no Serviço de Pronto Atendimento Virtual do Hospital Albert Einstein saltou de 1.200 para vinte mil pacientes ${ }^{2}$. Inúmeras empresas, surpreendidas pelo lockdown, tiveram que criar processos e infraestrutura de tecnologia em regime emergencial para evitar uma parada abrupta de seus negócios - e viram sair do papel em dias seus projetos de transformação digital que vinham em discussão há anos.

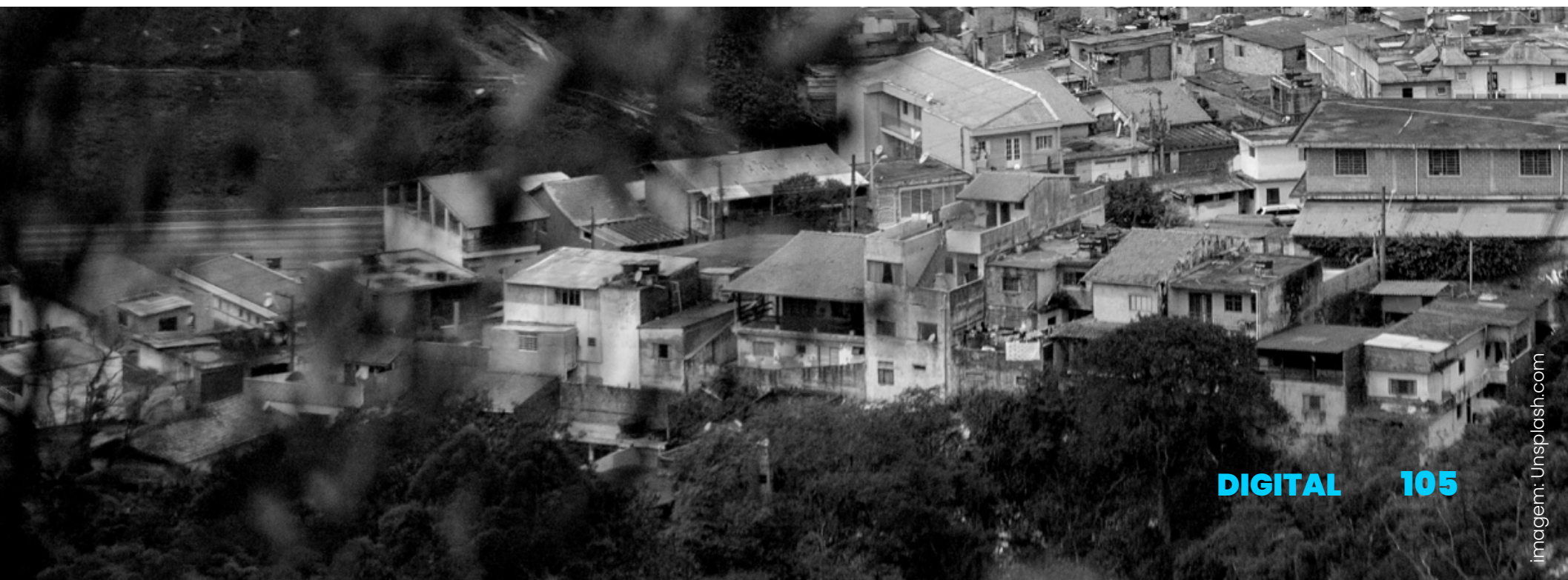


Estar preparado digitalmente tem feito bastante diferença durante essa terrível crise. Em um estudo publicado pela IBM, em 2021, em doze de dezoito indústrias pesquisadas, as organizações tech-savvy (ou seja, tecnologicamente capacitadas) tiveram uma performance de receita, em média, com seis pontos percentuais acima dos seus pares menos tecnológicos. No varejo, essa diferença chegou a dezesseis pontos percentuais ${ }^{3}$.

Todos esses exemplos corroboram a ideia de que toda a transição pela qual vínhamos passando desde o início do século, com o uso cada vez maior da internet, como plataforma de negócios, consolidou-se.

Agord, de foto, entrelmos ne ere digitel merecte pelo uso intensivo de teenologia, que vai desde eplieç̧êes extremamente sofisticadas até solução de questôes mais proscieds do nosso dị a dị, trazzendo uma série de beneff́cies como eonveniêneia, agilidade e seguranģ. Porém, a pandemia eseanẹrou allgo que já era latente: tcils benefícios não sc̃o igucllmente ceessíveis a todos.

Ao contrário, são restritos a um grupo privilegiado. Essa segregação digital já começa a ser apontada como uma ameaça à estabilidade da nossa sociedade. O Global Risks Report do World Economic Forum ${ }^{4}$ traz as questões de desigualdade digital e concentração de poder digital nas posições 6 e 7, respectivamente, entre os 10 maiores riscos globais mais prováveis.

Uma das grandes disrupções causadas pela pandemia foi no ensino. O fechamento das escolas trouxe um grande transtorno para crianças e famílias, porém, com consequências bem distintas, dependendo da condição socioeconômica da família. Enquanto nas famílias de maior poder aquisitivo a preocupação era ter banda larga suficiente para acomodar o trabalho dos pais, a escola e a Netflix ou o Fortnight, nas menos abastadas o problema era bem mais básico. Em agosto de 2020, o Gl apresentou a reportagem sobre Alan Somaville, um menino de 11 anos que estudava sob uma barraca de plástico feita pelo seu pai. A solução engenhosa visava proteger a criança do inverno rigoroso do Rio Grande Sul, para que pudesse ficar no único local na lavoura da família onde era possivel obter sinal de celular. A realidade de Alan infelizmente não é isolada. De acordo com dados do World 
Economic Bank, em 2019, apenas 67\% dos habitantes do Brasil tinham acesso à internet. Em países menos favorecidos, como Moçambique, esse número chega a $10 \%$. Globalmente falando, a cifra é de apenas $50 \%{ }^{5}$.

Uma das graves consequências da aceleração digital é o rápido deslocamento das oportunidades no mercado de trabalho. $O$ desaparecimento dos empregos analógicos e a geração de novas profissões acontecem quase simultaneamente, sem que haja tempo de readequação da infraestrutura de capacitação profissional ou dos ensinos fundamental e superior para prepararem os indivíduos às novas demandas do mercado. Isso leva a fortes contrastes. Por um lado, altíssimas taxas de desemprego e, por outro, inúmeros postos de trabalho não preenchidos por falta de profissionais qualificados. Em meados do ano passado, o Linkedln divulgou uma análise das profissões com maior demanda no mundo. Entre as dez primeiras, cinco estavam ligadas à tecnologia. Somadas, elas correspondiam a quase dezenove milhões de postos de trabalho, estando Desenvolvedor de Software na primeira posição, com quinze milhões de vagas abertas ${ }^{6}$.

A questão é complexa demais para ser resolvida exclusivamente por uma parcela da sociedade. Governos, empresas, instituições de ensino e organizações da sociedade civil precisam trabalhar de maneira colaborativa para corrigir essas distorções.

Pelo lado dos governos, a compreensão é de ser necessário criar um plano estratégico com o objetivo de desenvolver a infraestrutura e criar as habilidades necessárias para competir neste novo cenário. Países que não se posicionarem neste novo contexto poderão ver-se excluídos das cadeias produtivas globais. Por exemplo, em 2015, a China anunciou seu plano ambicioso para, em 2025, ser uma potência industrial e tecnológica - Made In China 2025. Dentre os objetivos, ser líder em inteligência artificial. O plano envolve altos investimentos do governo e seu apoio à iniciativa privada para desenvolvimento de novos negócios na área de tecnologia. É incontestável o quanto a tecnologia chinesa avançou nos últimos anos graças a essa estratégia. Outro excelente exemplo é a Estônia, um país que decidiu digitalizar cem por cento dos serviços do governo ao cidadão - em 2019, criou um plano para o país na área de inteligência artificial. Israel e Emirados Árabes são outros exemplos a serem seguidos de nações que vêm transformando suas vocações econômicas para capturar as oportunidades trazidas pela economia digital. Uma estratégia digital apoiada por um plano com metas claras serve para nortear uma série de decisões de investimento do orçamento fiscal, bem como a construção de parcerias público privadas para o desenvolvimento do país.

As empresas, por sua vez, cada vez mais terão que assumir o seu papel social de formadoras de pessoas e recapacitar seus funcionários - ao

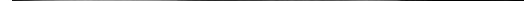


invés de simplesmente substituí-los. Também terão uma missão fundamental de, em conjunto, com o mundo acadêmico, criar currículos mais adequados para formar os perfis tanto técnicos quanto interpessoais dos profissionais que querem ter em seus quadros. Um exemplo disso é o programa P-Tech (Pathways in Technology Early College High School), uma parceria entre empresas e escolas públicas com o objetivo de capacitar os jovens para o mercado de trabalho. O programa, hoje, abrange mais de duzentas escolas - mais de cem mil estudantes e dezoito países. Na América Latina, o programa tem sido realizado principalmente através da parceria com Fé e Alegria, uma ONG focada na educação juvenil. As empresas apoiadoras do programa mentoram, apoiam e depois contratam os estudantes, fechando assim o ciclo.

As escolas, por outro lado, precisarão de reorientar a sua missão de provedoras de conteúdo para preparadoras de eternos aprendizes com curiosidade insaciável, através de atividades que privilegiem a experiência prática e a empregabilidade. Para citar como exemplo, um desenvolvedor de software será muito mais valorizado pela quantidade de revisões positivas no GitHub (um dos principais ecossistemas de desenvolvedores de software do mundo) sobre seu código do que por quais diplomas possui. Ou seja, estamos vivendo uma época de "mostre-me" ao invés de "diga-me". É fundamental que se acelere a curva de experiência dos jovens, permitindo, assim, uma rápida inserção no mercado de trabalho.

Sabendo das limitações dos governos - especialmente quando uma crise sanitária atingiu duramente os orçamentos planejados -, as entidades da sociedade civil passam a ter um papel essencial. Elas podem complementar o papel do governo com mais flexibilidade, agilidade e transparência, ampliando, assim, a possibilidade da participação da iniciativa privada nas ações que visam fomentar o processo de digitalização do país.

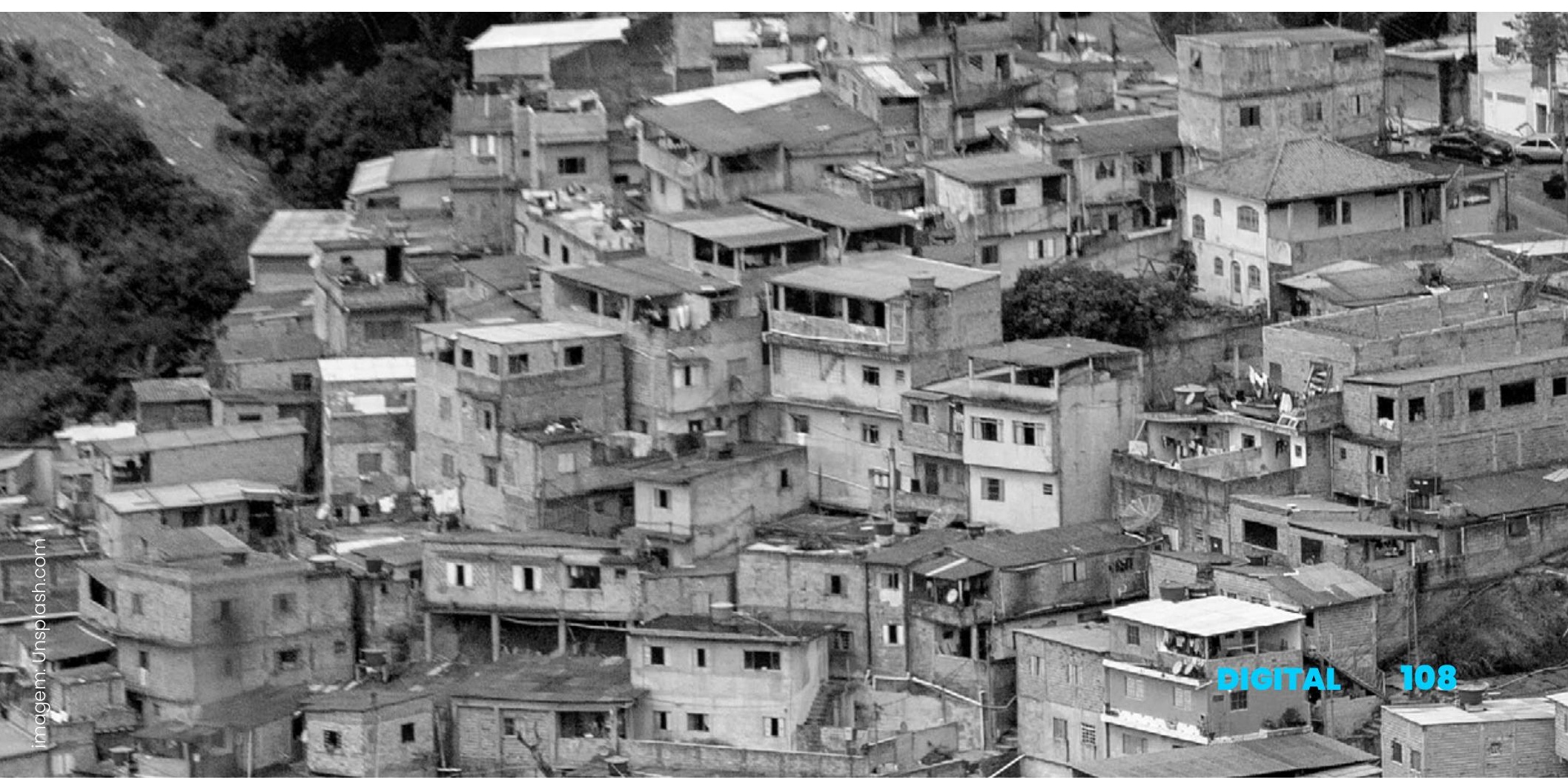


As teenologias digitcis têm o potencial de promover um novo salto de produtividade e bem-estar similar ao que a humanidade viu com a Revolução Industrial. Elas podem trazer a resolução para uma série de problemas que colocem em risco a sustentabilidade do planeta, tais como - aquecimento globalle a escassez de recursos naturais, como a ägua. Porém, nad a disso irá adiantar se no processo nä० tivermos um trabalho consciente e intencional de ampliar a inclusãoe permitir que mais e mais pessoas tenham acesso às oportunidades criadas por esta transformaçăo.

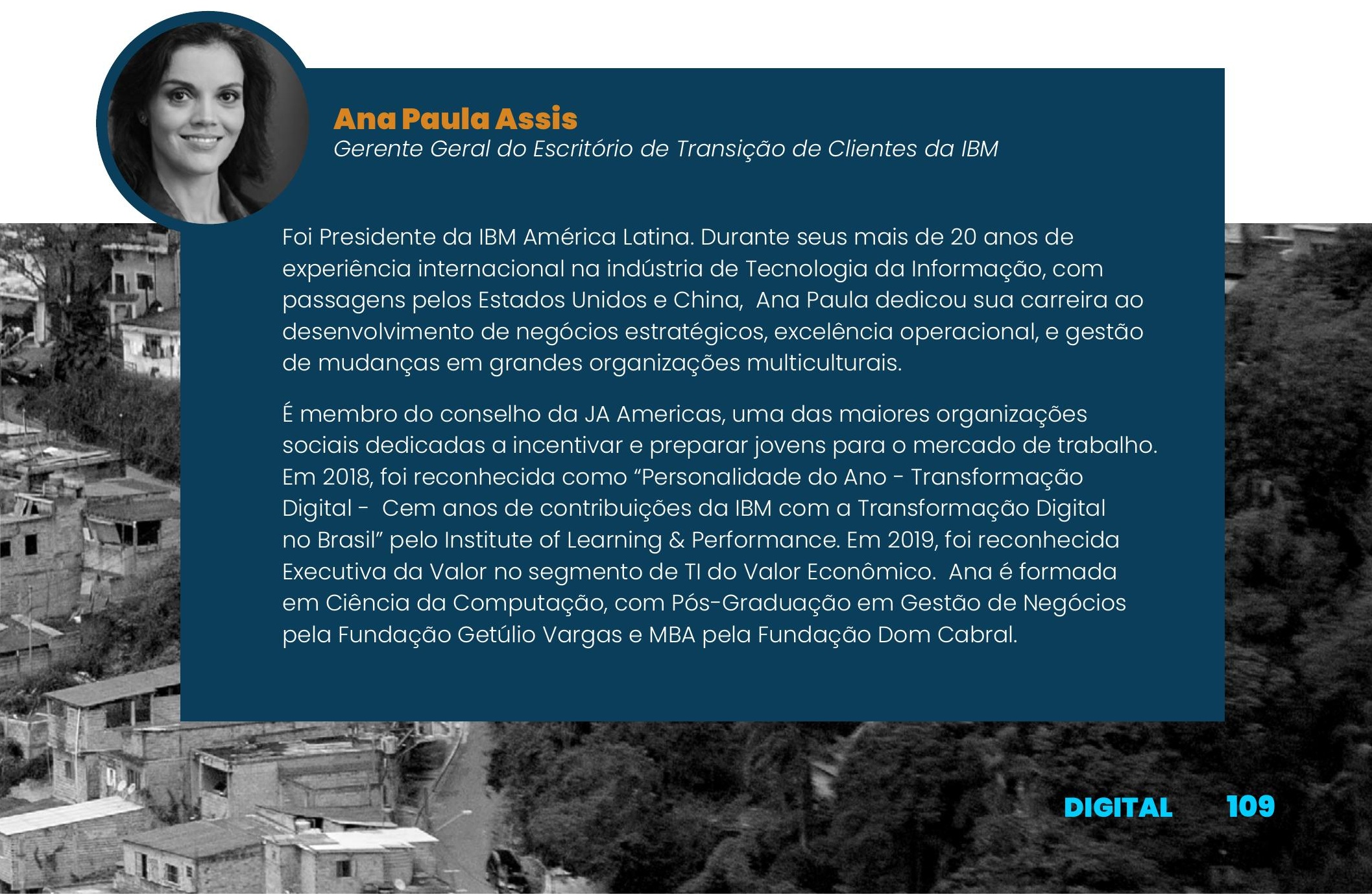




\section{NOTASEREFERÊNGIAS}

1 Galloway, Scott. "Post Corona: From Crisis to Opportunity", 2020, Penguim Random House

2 https://www.uol.com.br/vivabem/noticias/redacao/2020/09/23/telemedicina-cresce-no-brasil-atendimento-remoto-ajudou-salvar-pacientes.htm?cmpid=copiaecola

3 Digital Acceleration - Top technologies driving growth in a time of crisis, IBM Institute for Business Value

4 WEF, The Global Risks Report 2021, http://www3.weforum.org/docs/WEF_The_Global_ Risks_Report_2021.pdf

5 https://data.worldbank.org/indicator/IT.NET.USER.ZS?most_recent_value_desc=true

6 https://epocanegocios.globo.com/Carreira/noticia/2020/07/10-profissoes-mais-procuradas-do-mundo.html 